Revue

Revue de l'histoire des religions

de Ihistoire des religions

\title{
Alberto GUASCO, Cattolici e fascisti. La Santa Sede e la politica italiana all'alba del regime (1919-1925)
}

Bologna, Società Editrice Il Mulino (« Testi e ricerche di scienze

religiose », 50), 2013

\section{Laura Pettinaroli}

\section{OpenEdition \\ Journals}

Édition électronique

URL : http://journals.openedition.org/rhr/8628

DOI : $10.4000 /$ rhr.8628

ISSN : 2105-2573

\section{Éditeur}

Armand Colin

\section{Édition imprimée}

Date de publication : 1 septembre 2016

Pagination : 470-472

ISBN : 978-2-200-93061-5

ISSN : 0035-1423

Référence électronique

Laura Pettinaroli, «Alberto guAsco, Cattolici e fascisti. La Santa Sede e la politica italiana all'alba del regime (1919-1925) », Revue de l'histoire des religions [En ligne], 3 | 2016, mis en ligne le 06 octobre 2016, consulté le 25 septembre 2020. URL : http://journals.openedition.org/rhr/8628 ; DOI : https://doi.org/ 10.4000/rhr.8628

Ce document a été généré automatiquement le 25 septembre 2020.

Tous droits réservés 


\section{Alberto GUASCO, Cattolici e fascisti. La Santa Sede e la politica italiana all'alba del regime (1919-1925)}

Bologna, Società Editrice Il Mulino (" Testi e ricerche di scienze religiose », 50), 2013

\section{Laura Pettinaroli}

\section{RÉFÉRENCE}

Alberto GUASCO, Cattolici e fascisti. La Santa Sede e la politica italiana all'alba del regime (19191925), Bologna, Società Editrice Il Mulino (« Testi e ricerche di scienze religiose », 50), 2013, 21 cm, 575 p., $40 €$, ISBN 978-88-15-24520-5

1 Alberto Guasco, enseignant à la Link Campus University de Rome, livre ici le résultat de plusieurs années de recherche, menées au sein de la Fondation pour les sciences religieuses de Bologne et qui portent sur l'attitude du Saint-Siège face à la situation italienne entre 1919 et 1925 . Cette périodisation relève d'une volonté délibérée de mettre l'accent sur la phase initiale des relations entre Saint-Siège et fascisme, c'est-àdire sur les années du "fascisme-mouvement" et de l'installation au pouvoir de Mussolini, les lois fascistissimes de 1926 marquant l'avènement proprement dit du régime fasciste. La focalisation sur ces années permet de prendre à rebours les lectures tant démocrate-chrétiennes que totalitariennes, qui se sont plutôt intéressées au concordat de 1929 et aux crises de 1931 et 1938, pour d'évidentes raisons mémorielles et théoriques. Cette phase est également caractérisée par la présence d'un tiers - fort gênant pour le Saint-Siège - : le Parti populaire (PPI), acteur clé que le titre de l'ouvrage aurait pu mentionner. Après 1925, le Saint-Siège redevient l'unique interlocuteur de l'État sur la question religieuse et peut ouvrir le dossier de la conciliation.

2 Si l'historiographie sur les relations entre le fascisme et le Saint-Siège est extrêmement riche, l'auteur (dorénavant l'a.) justifie la nécessité de reprendre l'étude à la fois par 
des raisons historiographiques (avènement d'une histoire religieuse plus diversifiée) et archivistiques. En effet, l'ouverture des archives vaticanes pour la période Benoît XV (1914-1922, en 1985) et Pie XI (1922-1939, en 2006) permet de saisir de l'intérieur la position du Saint-Siège. De plus, l'ouverture des archives vaticanes a incité d'autres acteurs religieux à donner accès à leurs fonds, comme la Curie généralice des jésuites (ARSI - dont l'a. utilise le fonds Tacchi Venturi) et la Civiltà cattolica, revue des jésuites romains souvent considérée comme la voix officieuse du pape. Si Guasco avait déjà fait connaître certains de ses résultats dans des articles (signalés p.9-10), le présent ouvrage synthétise sa réflexion et publie 150 documents originaux (p. 299-547). L'a. reprend donc le style "documentaire » de nombreux ouvrages sur le Saint-Siège et l'Italie, dans la tradition de Francesco Margiotta Broglio (Italia e Santa Sede, dalla grande guerra alla conciliazione: aspetti politici e giuridici, 1966), Pietro Scoppola (La Chiesa e il fascismo: documenti e interpretazioni, 1971) ou, plus récemment, de Giovanni Sale (Fascismo e Vaticano prima della conciliazione, 2007).

3 Le premier chapitre (p. 15-81) présente la riche historiographie sur les relations entre l'Italie et le fascisme de façon synthétique et complète, en intégrant les recherches classiques et récentes menées en italien, anglais, allemand et français (le lecteur francophone regrettera toutefois ici les coquilles). L'a. rappelle les étapes de cette historiographie, marquée par une approche juridique (Jemolo, Margiotta Broglio) qui se diversifie progressivement vers l'étude de l'antisémitisme (Miccoli) ou de la vie religieuse (De Rosa).

4 Les trois chapitres suivants proposent une approche chronologique des relations entre le Saint-Siège et l'Italie durant la première moitié des années 1920, en identifiant deux tournants : la marche sur Rome de 1922 et la campagne électorale de 1924.

5 Le chapitre II (p. 83-154) est ainsi consacré à la crise italienne de l'après-guerre (1919-1922). Après avoir rappelé la conciliation ratée de juin 1919 du fait de l'opposition du roi, l'a. montre comment Mussolini, de formation anticléricale, décide d'intégrer dès 1919 la Rome catholique à sa vision du monde. Alors que le Saint-Siège est surtout préoccupé par le PPI, le fascisme passe plutôt inaperçu dans les sources vaticanes jusqu'en octobre 1922. L'analyse fine de la presse vaticane permet toutefois de montrer qu'à partir des événements du Palazzo d'Accursio à Bologne (21 novembre 1920), la violence fasciste est rejetée mais aussi distinguée de la violence socialiste, jugée directement attentatoire à l'ordre.

6 Le chapitre III (p. 155-231) analyse une période bien différente car le Saint-Siège doit prendre position à l'égard du gouvernement dirigé par Mussolini (1922-23). Le coup d'État lui-même, malgré son inconstitutionnalité, n'est pas rejeté et, surtout, les mesures favorables à l'Église (crucifix dans les écoles, enseignement religieux) séduisent. La realpolitik menée par Gasparri (qui rencontre secrètement Mussolini en janvier 1923) est cependant mâtinée d'attentisme nourri de scepticisme quant à la pérennité du nouveau gouvernement. L'attitude du PPI, qui refuse en avril 1923 toute collaboration avec les fascistes, au grand dam du Saint-Siège qui aurait préféré le maintien de Populaires au gouvernement pour en modérer les tendances laïcistes, précipite la démission de don Sturzo en juillet, directement provoquée par le SaintSiège. Les violences contre les organisations religieuses atteignent cependant leur apogée avec le meurtre de don Giovanni Minzoni, le 23 août 1923 à Argenta.

7 Le chapitre IV est consacré à l'année 1924-1925 (p. 233-296). Après la dissolution de la Chambre en janvier 1924 s'ouvre une période électorale durant laquelle se multiplient 
les violences contre les opposants à la liste fasciste. Pie XI dénonce ces violences en consistoire (24 mars 1924) et Gasparri écrit à Mussolini le 31 mars pour se plaindre des exactions contre les opposants, y compris non catholiques. Cependant, la voie choisie par le PPI sous la direction de De Gasperi - celle du rapprochement avec les socialistes est fermement combattue par le Saint-Siège, notamment par le biais d'articles de l' Osservatore romano et de la Civiltà cattolica, auxquels Gasparri contribue directement. La peur d'une guerre civile après l'enlèvement de Matteotti (10 juin) confirme le SaintSiège dans une recherche d'ordre. Si le Saint-Siège utilise la presse à Rome, il met également à contribution son réseau diplomatique pour agir à l'étranger. Ainsi, alors que Mussolini laisse sans réponse la lettre du 31 mars 1924, Gasparri la transmet aux nonces en France et en Allemagne, ainsi qu'au cardinal Bourne en Angleterre, pour faire connaître la «terreur» fasciste dans la presse au-delà des Alpes (p. 245). Cette approche globale, propre à l'administration vaticane, est malgré tout tardive : ce n'est qu'en septembre 1924 que Gasparri lance une enquête auprès des nonces en Belgique, Autriche et Allemagne sur les alliances entre socialistes et catholiques dans ces pays (p. 275).

8 L'ample partie documentaire du volume donne essentiellement accès à des sources d'archives vaticanes, en particulier de l'Archivio segreto vaticano (Nonciature d'Italie, Secrétairerie d'État) et des archives historiques de la Secrétairerie d'État (Congrégation pour les Affaires ecclésiastiques extraordinaires, fonds Italia et Stati ecclesiastici). De nombreux documents émanent de Pietro Gasparri, secrétaire d'État, mais aussi d'autres cardinaux et diplomates vaticans ou encore de personnalités comme le jésuite Pietro Tacchi Venturi ou don Luigi Sturzo. Les interventions personnelles des papes - certes rares - sont frappantes comme la lettre de Benoît XV à l'évêque de Trieste du 2 août 1921, dans laquelle le pape réagit aux violences dont sont victimes les prêtres slaves (doc. 34) ou encore la note manuscrite dans laquelle Pie XI demande de « consoler » un évêque confronté aux violences fin 1922 (doc. 55). Les documents choisis donnent un aperçu complet sur cette période, même si on pourrait discuter le choix de republier des articles de presse ou des documents déjà édités par d'autres chercheurs. Les documents vraiment inédits et qui semblent les plus neufs sont les rapports des évêques italiens au Saint-Siège sur les violences fascistes, dont l'auteur aurait pu proposer une analyse plus précise et une cartographie.

9 En définitive, l'ouvrage offre une synthèse, à jour d'une historiographie renouvelée, sur les relations entre le Saint-Siège et l'Italie au début des années 1920, ainsi que de précieuses ressources documentaires. De plus, en mettant à profit de nouvelles archives, l'a. contribue au renouvellement d'une historiographie qui datait des années 1960-1970. On pourra toutefois regretter qu'au sein d'une approche très politique, l'a. n'ait pas utilisé de façon plus systématique des sources émanant de l'État italien, du parti fasciste ou même du parti socialiste. Enfin, malgré l'intérêt pour la communication politique par la presse écrite, l'a. n'ouvre pas l'analyse vers l'investissement symbolique du politique (cas des bénédictions de drapeaux) ou vers la dimension théologico-politique, notamment les enjeux italiens de la fête du Christ-Roi instituée en 1925. La période choisie permet cependant d'ouvrir la réflexion sur des thèmes qui ont été importants dans les années 1930 et au-delà, à savoir la question du «bon » nationalisme ou encore la possibilité d'une collaboration avec les socialistes. En ce sens, cet ouvrage intéressera non seulement les spécialistes de l'Italie et des 
totalitarismes mais aussi tous ceux qui s'interrogent sur le christianisme en politique et la problématique de la violence.

\section{AUTEURS}

\section{LAURA PETTINAROLI}

Institut Catholique de Paris. 